\title{
Mitigation of Unbalanced Voltage Sags and Swells of Power System in Utility Side by using Sen Transformer
}

\author{
Loveswara Rao ${ }^{1}$.Burthi, P.S.Prema Kumar ${ }^{2}$ \\ ${ }^{1}$ Professor, Department of EEE, Koneru Lakshmaiah Education Foundation, Guntur, Andhra Pradesh, India \\ ${ }^{2}$ Assistant Professor, Department of Mechanical Engineering, Koneru Lakshmaiah Education Foundation, \\ Guntur, Andhra Pradesh, India \\ *Corresponding Author E-mail: loveswararao@kluniversity.in
}

\begin{abstract}
Majority of the industrial electrical loads requires balanced three phase supply but in reality there is unbalanced supply due to single phase loads like railway tracks etc.increasing use of non linear loads in modern power distribution network there are some power quality issues like voltage sags and voltage swells, this distortion of the power supply effect the loads which are connected to power distribution network. In order to improve quality of the power, in this paper a Sen Transformer (ST) technique as been proposed to minimize unbalanced voltage sags and swells. The proposed technique mitigates both voltage sag and swell during balanced and unbalanced operating conditions. The proposed ST consists of a programmable tap controller to compensate ride through faults in power system network. The proposed work as been implemented using MATLAB/SIMULINK software. To validate the proposed work, simulation results are presented.
\end{abstract}

Keywords: Sen Transformers (ST) Unbalanced Voltage sag Voltage swell Control logic Unbalance Mitigation

\section{Introduction}

The uneven distribution and continuous variation of single phase loads across the three phase power system is the main cause for the voltage unbalance. Another cause for unbalance is long duration of asymmetrical faults. The occurrence of faults result in either sag or swell in the wave form. The consequences of voltage sags for various loads are presented in [2], [3].The unbalanced power is applied to the electric devices, it gives a difficult problem to them, especially the electric motors. During the operation at unbalanced voltage conditions, there will be decrease in the efficiency of induction motor. The increase in the heating of the winding of the induction motor leads to its failure. Both stator and rotor get heated up highly due to the induction motor problems like mechanical damage of bearings. This leads to thermal ageing. The motor cannot produce full torque due to negative sequence system because it produces reverse rotating magnetic field. In most practical cases, the asymmetry of the loads is the main cause of unbalance. As per the department of energy of United States, seventy percent of the electricity is consumed by industrial motors, and in typical firms eighty percent of the load consists of three-phase AC induction motors [1]. In Doubly Fed Induction Generators (DFIGs) the rotor currents are suddenly increased due to voltage sags on grid side and these currents are damaging the rotor side converters [4], [5].

All these complications are reduced by using Sen Transformer. Sen Transformer is one of the power flow controlling transformers. This transformer provides the independent control of both active and reactive power flows [6]. To control the power flow in transmission line, the ST provides two main functions, one is voltage regulation and another one is impedance regulation [7],[8]. As a power flow controller the complete details of ST is given in [9].The proposed ST mitigates voltage sags for ride through the grid inter connected DFIG wind turbine during symmetrical faults [10]. Compared to power electronic Compensator circuits like DVR, Sen Transformer is more cost effective and high reliable [11],[12].

Section 2 deals with the principle of operation of Sen Transformer and implementation of the proposed control logic. In section 3, results are discussed which show the performance of proposed control logic and section 4 concludes the key points of the paper.

\section{Description of Proposed Work}

\subsection{Principle of Operation of Sen Transformer}

The Sen Transformers are having two main parts, first one an exciter unit and ad second one a compensating unit. Nine single phase transformers are arranged in such a way that in each phase there are three transformers in the ST unit. The primary and secondary windings of ST are connected as shown in Fig. 1. There are four tapping per each secondary winding and a total of 36 tapings in the secondary winding of the Sen Transformer. As per the required voltage level these tapings can be changed. 
Table 1: Seven types of dip (based on [13]); $k$, residual voltage (pu)

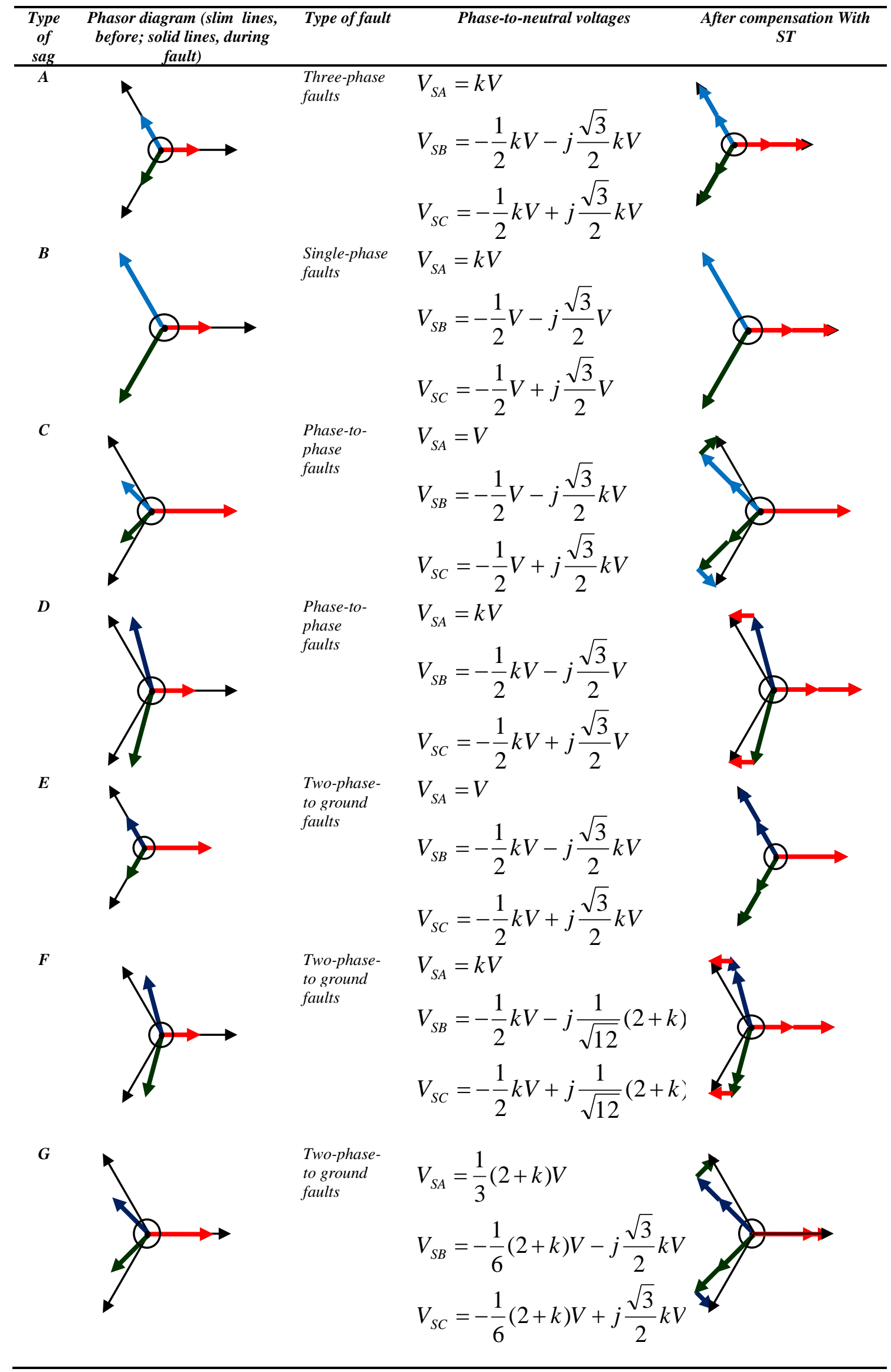


These tappings provide low cost voltage regulation on a transmission line. The ST is connected between the load side utility and the power supply grid so that whenever there are defects in the transmission system which leads to voltage sag is compensated by ST. If there is no defect in the transmission system, the power from source is given to the grid directly and if there is fault in the transmission system the power from source is diverted to the load through Sen Transformer, where it is restored.

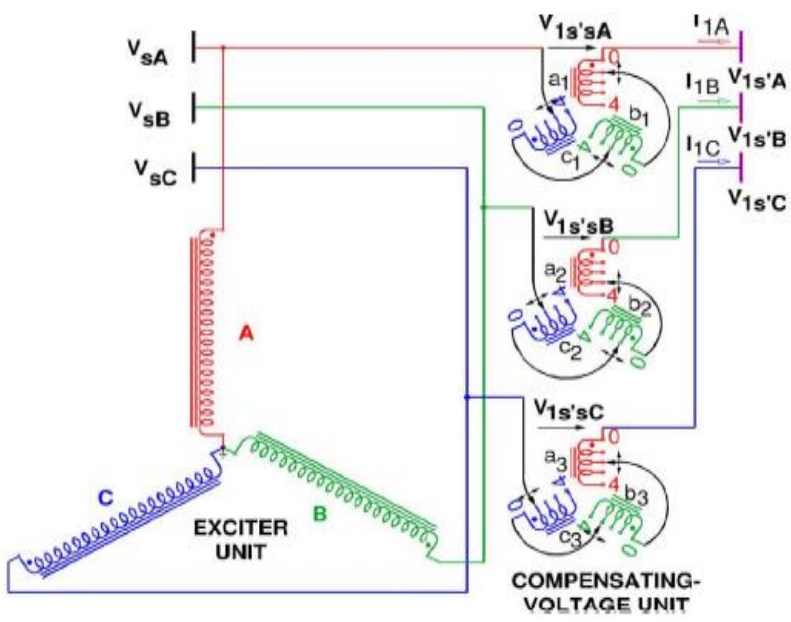

Fig. 1: Sen Transformer Primary and secondary windings Connection

\subsection{Types of Sags}

The nature of the voltage dip/sag depends up on nature of fault and transformer winding connections which are connected between fault locations and consider point of the system. Bollen categorized 7 types of dips (A to G) [13]. The ST compensates all kinds of voltage dips as shown in Table 1 . Here $k$ is voltage dip depth factor and $V$ is corresponding reference phase voltage $(1 \mathrm{pu})$.

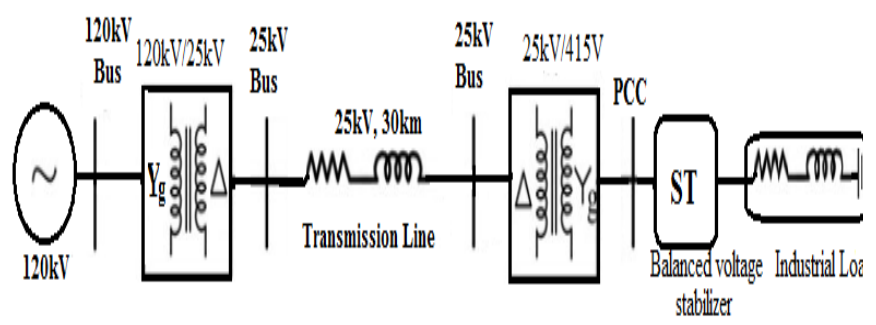

Fig. 2: Single line diagram for $3 \varnothing$ power system with balanced voltage stabilizer

\subsection{Voltage balancing description at utility side through Sen Transformer under unbalanced voltage sags}

The Fig. 2 shows the single line diagram for three phase power system with balanced voltage stabilizer for utility. The industrial load is connected to distribution transformer in series with ST. Here the ST is acting as a balanced voltage stabilizer. The block diagram for the operation of the Sen Transformer is shown in Fig. 3, where the output voltage range from the transformers is controlled by the triggering the GTO(Gate Turn Off) switches whose gate triggering signal is controlled by the control logic, in which the code is embedded. Both voltage sensors and phase angle sensors are operated at low voltage level. The voltage deviation of the system depends upon the severity of the fault condition. Based on the data of voltage sensor and phase angle sensor, the control block gives gate pulses to GTO switches to compensate the voltage for load with in $\pm 10 \%$ tolerance from normal magnitude and $\pm 5 \%$ tolerance from normal phase angle.

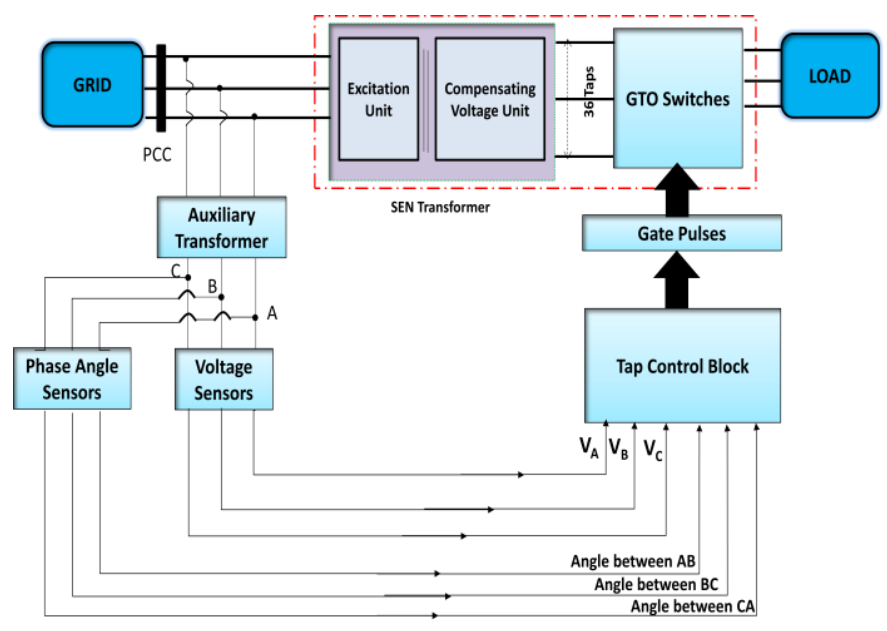

Fig. 3: Block diagram for the operation of the Sen Transformer with tap control block

\subsection{Implementation of Proposed Methodology}

The proposed work has been implemented using Matlab/Simulink software. There are three transformers in each phase. So, total nine transformers for three phases one transformer in each phase is used to compensate voltage magnitude and remaining two transformers in each phase are used to compensate the phase angle. There are 3 circuit breakers found in the Fig. 4, namely CB$1, \mathrm{CB}-2$ and CB-3.If there is no fault in the power system network, then $\mathrm{CB}-1$ is in operation by giving control signal 'A1'to $\mathrm{CB}-1$. If there is a problem in the network of the power system, CB-2 and CB-3 receive control signals 'A2' and 'A3' to enable $\mathrm{ST}$ to operate. Voltage sags and also voltage swells mitigated, $\mathrm{CB}-$ 1control signal is deactivated simultaneously, then CB-1 is in off position and clears the way for ST for the faults mitigation. The nine transformers of ST are controlled using control block, this is a logic generated tap that means this control block generates gate pulses for Gate Turn Off switches which are controlling the tapings of Sen Transformer`s all three phases .

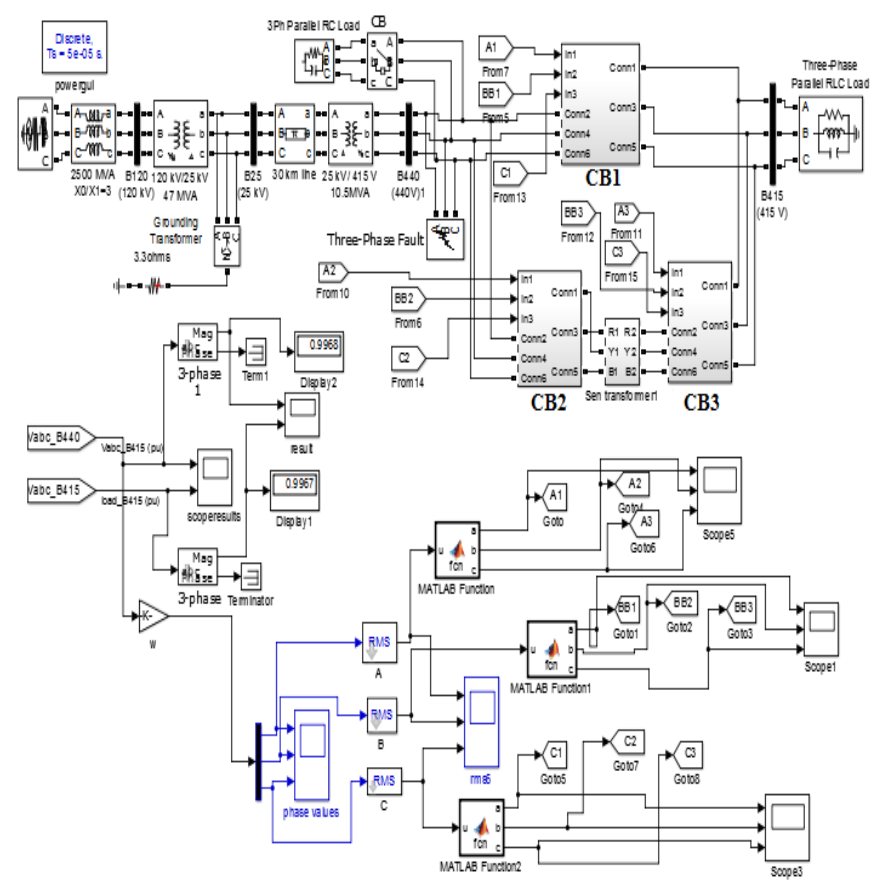

Fig. 4: MATLAB/SIMULINK diagram for mitigation of unbalanced voltage sags and swells of power system at utility side through Sen Transformer technique. 


\section{Results and Discussion}

\subsection{LLLG Fault}

The total simulation period is taken 0.5 seconds. At grid side $0.004 \Omega$ fault impudence is introduced to create voltage sag $(0.5 \mathrm{pu})$ between 0.2 to 0.4 seconds as shown in Fig. 5. The ST identified the sag and selected the suitable tapings as for the program logic in order to reduce the sag and to bring the approximately normal value $(0.96 \mathrm{pu})$ between 0.2 to 0.4 seconds as shown in Fig. 6.

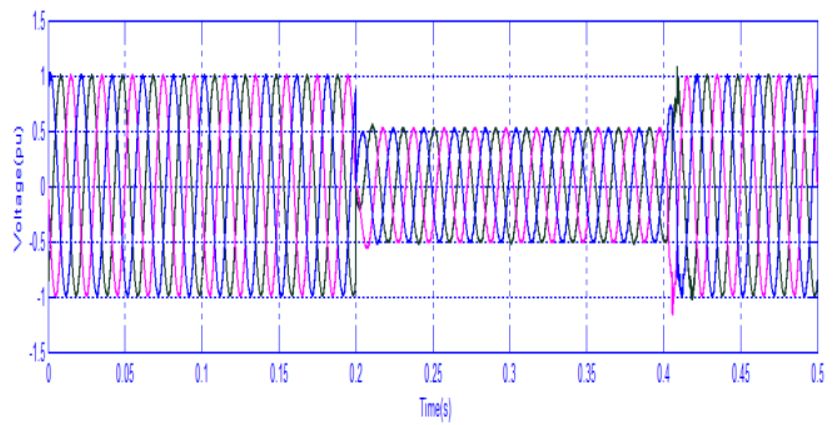

Fig. 5: Grid side voltages without ST during LLLG Fault

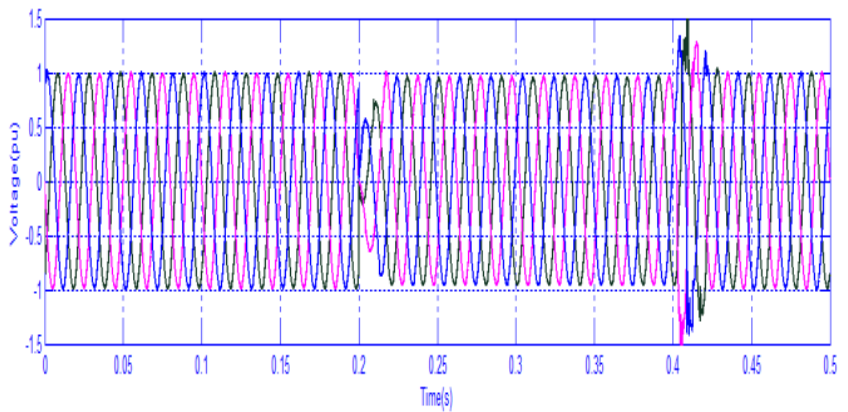

Fig. 6: Mitigation of voltage sag at utility side by using ST

\subsection{LG Fault}

The phase B is grounded with fault impedence of $0.004 \Omega$ to create unbalanced voltage sag in between 0.2 to 0.4 seconds as shown in Fig. 7. In this period the grid voltages $\mathrm{V}_{\mathrm{AB}}$ is $0.72 \angle 0^{\circ} \mathrm{pu}$, voltage $\mathrm{V}_{\mathrm{BC}}$ is $0.77 \angle-114^{0}$ pu and voltage $\mathrm{V}_{\mathrm{CA}}$ is $1.09 \angle 108^{0} \mathrm{pu}$. The ST identified the voltage sag and phase angle between them and selected the suitable tapings as for the program logic in order to reduce the voltage unbalance. The ST mitigates these unbalanced voltages effectively as shown in Fig. 8 between 0.2 to 0.4 seconds. After compensating with ST the utility side voltage $\mathrm{V}_{\mathrm{AB}}$ is $0.98 \angle 0^{0} \mathrm{pu}$, voltage $\mathrm{V}_{\mathrm{BC}}$ is $1.01 \angle-114^{0}$ pu and voltage $\mathrm{V}_{\mathrm{CA}}$ is $1.07 \angle 118^{\circ} \mathrm{pu}$.

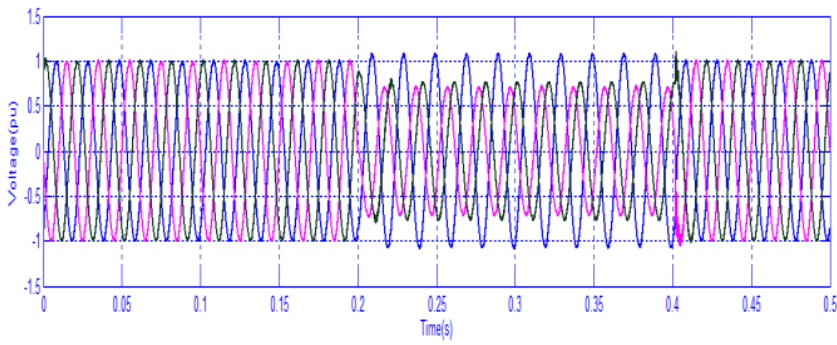

Fig. 7: Grid side voltages without ST during LG Fault

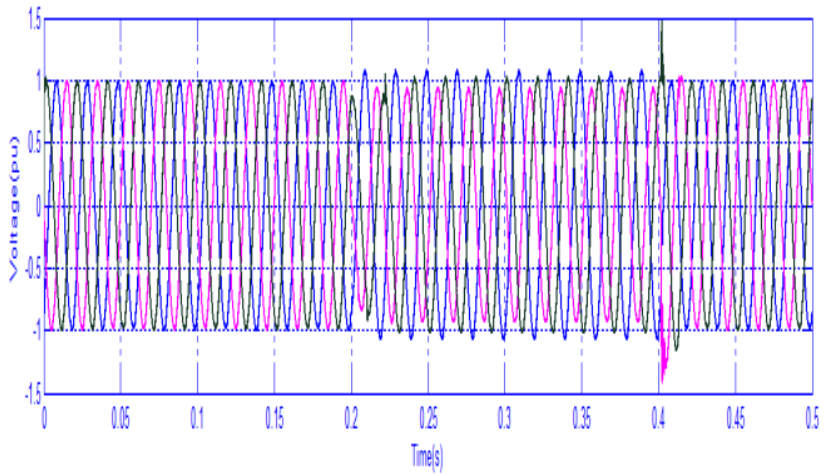

Fig. 8: Mitigation of unbalance voltage sags at utility side by using ST during LG fault

\subsection{LLG Faults}

In another case the phase $\mathrm{B}$ and phase $\mathrm{C}$ are grounded with impedence of $0.004 \Omega$. Then the voltage sag is occurred between 0.2 to 0.4 seconds as shown in Fig. 9. In this period the grid voltages $\mathrm{V}_{\mathrm{AB}}$ is $0.77 \angle-48.6^{0} \mathrm{pu}$, voltage $\mathrm{V}_{\mathrm{BC}}$ is $0.464 \angle-138^{0}$ pu and voltage $\mathrm{V}_{\mathrm{CA}}$ is $0.89 \angle 107^{0} \mathrm{pu}$. The ST identified the voltage sag and phase angle between them and selected the suitable tapings as for the program logic in order to reduce the voltage unbalance. The ST mitigates these unbalanced voltages effectively with in acceptable limits between 0.2 to 0.4 seconds as shown in Fig. 10. After compensating with ST the utility side voltage $\mathrm{V}_{\mathrm{AB}}$ is $1.05 \angle 0^{0} \mathrm{pu}$, voltage $\mathrm{V}_{\mathrm{BC}}$ is $0.92 \angle-118^{\circ} \mathrm{pu}$ and voltage $\mathrm{V}_{\mathrm{CA}}$ is $1.02 \angle 119^{\circ} \mathrm{pu}$.

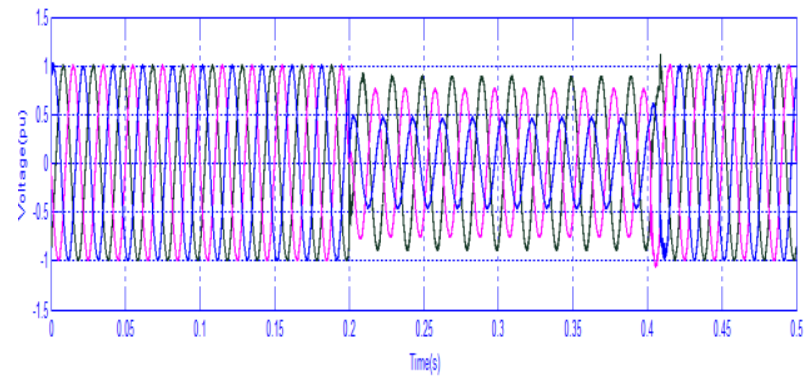

Fig. 9: Grid side voltages without ST during LLG Fault

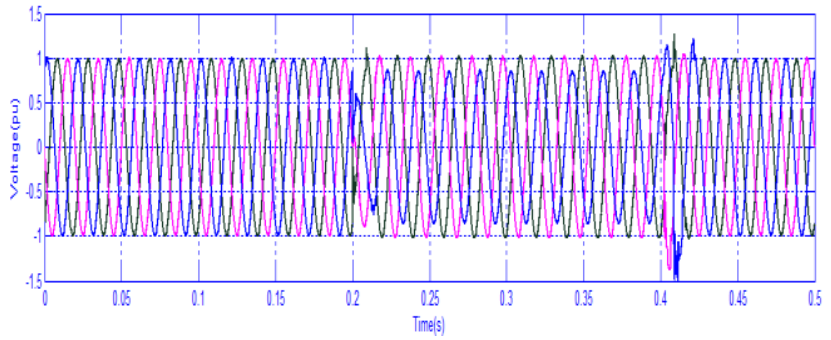

Fig. 10: Mitigation of unbalance voltage sags at utility side by using ST during LLG fault

\subsection{Voltage Swell}

The total simulation period is taken 0.5 seconds. At grid side 6.5MVAR capacitive reactive power is injected from outside source for creating voltage swell $(0.26 \mathrm{pu})$ in between 0.2 to 0.4 second as shown in Fig. 11. The ST identified the swell and selected the suitable tapings as for the program logic in order to reduce the swell and to bring to the normal value (1pu) as shown in Fig. 12. 


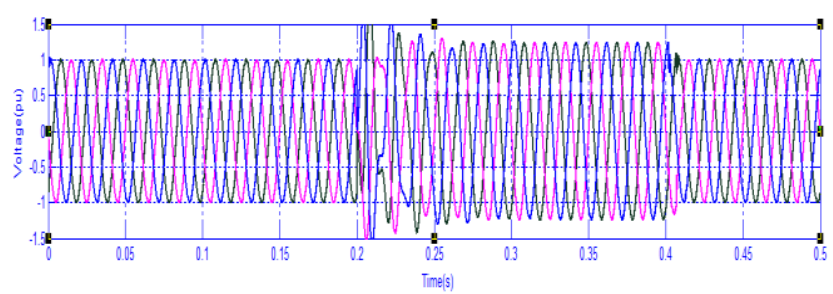

Fig. 11: Grid side voltage without ST

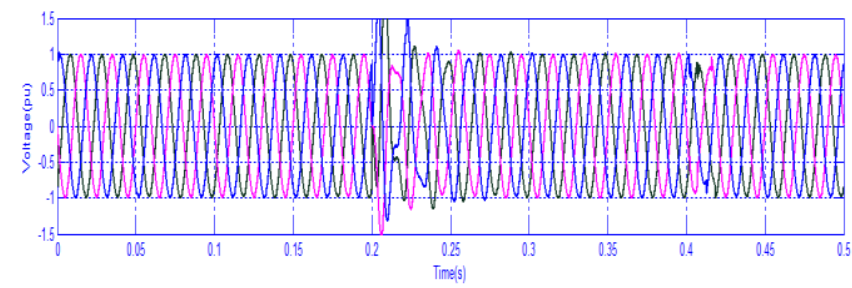

Fig. 12: Mitigation of voltage swells at utility side by using ST
The traditional fast on load tap changing voltage regulator is able to regulate voltage magnitude only [14]. But the proposed ST is able to control both magnitude and phase angle of the voltage of the system. So it mitigates unbalanced voltage sags and swells very effectively within acceptable limits. Dynamic Voltage Restorer (DVR) and Unified Power Quality Conditioner (UPQC) are also very popular to mitigate voltage sags and swells [15]. This DVR consists of voltage source convertor, battery energy storage system, boosting transformer, harmonic reduction filter and DC charging unit. Similarly the UPQC consists of two back to back bi- directional connected voltage source convertors, common DC link and an insertion transformer. Due to limited storage capacity the above devices mitigate voltage sags for limited period only. But the proposed method has no storage elements. So it mitigates voltage sags or swells for unlimited period effectively. Consolidated results of ST are shown in Table 2.

Table 2. Consolidated results of ST for varius fault mitigations

\begin{tabular}{|c|c|c|c|}
\hline Sl.NO & $\begin{array}{l}\text { Nature of } \\
\text { the Fault }\end{array}$ & Voltage at grid side in per unit(pu) & $\begin{array}{c}\text { Compensated voltage at utility side } \\
\text { with ST in pu }\end{array}$ \\
\hline \multirow{3}{*}{1} & \multirow{3}{*}{ LLLG } & $V_{A B}=0.5 \angle 0^{0}$ & $V_{A B}=0.96 \angle 0^{0}$ \\
\hline & & $V_{B C}=0.5 \angle-120^{\circ}$ & $V_{B C}=0.96 \angle-120^{\circ}$ \\
\hline & & $V_{C A}=0.5 \angle 120^{\circ}$ & $V_{C A}=0.96 \angle 120^{\circ}$ \\
\hline \multirow{3}{*}{2} & \multirow{3}{*}{ LLG } & $V_{A B}=0.77 \angle-48.6^{0}$ & $V_{A B}=1.05 \angle 0^{0}$ \\
\hline & & $V_{B C}=0.464 \angle-138^{0}$ & $V_{B C}=0.92 \angle-118^{0}$ \\
\hline & & $V_{C A}=0.89 \angle 107^{0}$ & $V_{C A}=1.02 \angle 119^{0}$ \\
\hline \multirow{3}{*}{3} & \multirow{3}{*}{ LG } & $V_{A B}=0.72 \angle 0^{0}$ & $V_{A B}=0.98 \angle 0^{0}$ \\
\hline & & $V_{B C}=0.77 \angle-114^{0}$ & $V_{B C}=1.01 \angle-114^{0}$ \\
\hline & & $V_{C A}=1.09 \angle 108^{0}$ & $V_{C A}=1.07 \angle 118^{0}$ \\
\hline \multirow{3}{*}{4} & \multirow{3}{*}{$\begin{array}{c}\text { During } \\
\text { Voltage } \\
\text { swell }\end{array}$} & $V_{A B}=1.26 \angle 0^{0}$ & $V_{A B}=1 \angle 0^{0}$ \\
\hline & & $V_{B C}=1.26 \angle-120^{\circ}$ & $V_{B C}=1 \angle-120^{\circ}$ \\
\hline & & $V_{C A}=1.26 \angle 120^{\circ}$ & $V_{C A}=1 \angle 120^{\circ}$ \\
\hline
\end{tabular}

\section{Conclusion}

From the results obtained in this paper, it can be concluded that Sen Transformer can be used to compensate the voltage sags or swells during faults in the power system by automatic tap changing control principle. ST compensates the voltage sags and swells under balanced and unbalanced load conditions. ST is low cost device with less design complexity and low power losses and high reliability. The advantage of ST is that it can compensate long duration faults. Induction motors are popularly used in almost every industry, when they are supplied with unbalanced voltages their efficiency reduces, life time decreases and annual maintenance cost increases. Thus with Sen Transformer technique the induction motor is protected from unbalances along with increased efficiency and less maintenance cost.
Appendix

Parameters of Sen Transformer: MVA $=2$, voltage ratio $a=3: 4$, excitation winding resistance $=0.0008 \mathrm{pu}$, compensated winding resistance $=0.0008 \mathrm{pu}$. Leakage inductance of both excitation and compensated windings $=0.1 \mathrm{pu}$.

Load details: Active power $\mathrm{P}=120 \mathrm{KW}$, Inductive reactive power $\mathrm{Q}_{\mathrm{L}}=1000 \mathrm{VAR}$, capacitive reactive power $\mathrm{Q}_{\mathrm{C}}=100 \mathrm{VAR}$.

\section{References}

[1] O. Souto, J. Oliveira, and L. Neto, , "Induction motors thermal behavior and life expectancy under non ideal supply conditions," in IX Int. Conf. Harmonics and Quality of Power, Orlando, FL, 2000 . 
[2] Rajesh Damaraju, S.V.N.L. Lalitha. "A Fuzzy Controller for Compensation of Voltage SAG/SWELL Problems Using Reduced Rating Dynamic Voltage Restorer" TELKOMNIKA Indonesian Journal of Electrical Engineering VOL. 15, No 3: September 2015, pg no: 407-414.

[3] S.N.V.Ganesh, K.Ramesh Reddy, B.V.Shankar Ram. "Comparison of different control strategy basedon pole placement for cascade multilevelinverter based dynamic voltage restorer" in Journal of Electrical Systems, VOL.10, No.1, March 2010.

[4] Dileep Kumar Varma, Y. P. Obulesh, Ch. Sai Babu. "Decoupled Feed Forward Voltage Oriented Controller for DFIG under Balanced and Unbalanced Fault Conditions" TELKOMNIKA Indonesian Journal of Electrical Engineering VOL. 15, No 2: August 2015, pg no: 209-216.

[5] Omer Elfaki Elbashir, Wang Zezhong, Liu Qihui. "Behavior of DFIG Wind Turbine during Unbalanced Grid Voltage" TELKOMNIKA Indonesian Journal of Electrical Engineering VOL. 12, No 7: July 2014, pg no: 4934-4943.

[6] Kalyan K. Sen and Mey Ling Sen., "Introducing the Family of "Sen" Transformers: A Set of Power Flow Controlling Transformers" in IEEE Transactions on Power Delivery, VOL. 18, NO. 1, JANUARY 2003.

[7] M. Omar Faruque and Venkata Dinavahi., "A Tap-Changing Algorithm for the Implementation of "Sen" Transformer" in IEEE Transactions on Power Delivery, VOL. 22, NO. 3, JULY 2007

[8] Raju Jayaraman, Kowslaya M. "Evolve the Controller for Static Synchronous Series Compensator Based on Control Strategy of Sen Transformer' IJPEDS Vol 4, No 1: March 2014, pg no: 127136.

[9] M. Omar Faruque, Student Member, IEEE, and Venkata Dinavahi, Member, IEEE: "Detailed Real-Time Transient Model of the "Sen" Transformer". IEEE transactions on power delivery, vol. 23, no. 3, July 2008.

[10] Burthi Loveswara Rao and P. Linga Reddy., "An LVRT Solution for DFIG Wind Turbine during Symmetrical Grid Fault by using "Sen" Transformer" in Indian Journal of Science and Technology, Vol 8(36), DOI: 10.17485/ ijst/2015/v8i36/71809, December 2015.

[11] Loveswara Rao.Burthi, P. Linga Reddy and B.L.N.V.S.K.Siva Prakash., "An Active Dynamic LVRT Solution for Balanced and Unbalanced Grid Faults in a Power System by Using "Sen" Transformer" in 2014 Annual IEEE India Conference (INDICON)

[12] Burthi LR and Lingareddy P, "Comparison of "sen" transformer with dvr for lvrt solution of dfig wind turbine" in Journal of Electrical Engineering, www.jee.ro 2016 March; edition-16, Vol.1: P1-8.

[13] Bollen M. H. J., Understanding power quality problems - voltage sags and interruptions, IEEE Press Series on Power Engineering, 2000 .

[14] R. Echavarría, A. Claudio, and M. Cotorogea, "Analysis, Design, and Implementation of a Fast On-Load Tap Changing Regulator" in Proc. IEEE Power Electron.vol.22, no.3, pp.527-534, March2007.

[15] Y.Kusuma Latha, Ch.Saibabu, and Y.P.Obulesu "Unified Power Quality Conditioner for Voltage Sag and Harmonic Mitigation of Nonlinear Loads' IJPEDS Vol .1, No 1: September 2011, pg no: 65-74.

[16] Avinash Yadlapati, Dr. Hari Kishore Kakarla, "An Advanced AXI Protocol Verification using Verilog HDL", Wulfenia Journal, ISSN: 1561-882X, Volume 22, Number 4, pp. 307-314, April 2015

[17] P Ramakrishna, K. Hari Kishore, "Design of Low Power 10GS/s 6-Bit DAC using CMOS Technology "International Journal of Engineering and Technology (UAE), ISSN No: 2227-524X, Vol No: 7, Issue No: 1.5, Page No: 226-229, January 2018.

[18] A Murali, K. Hari Kishore, "Efficient and High Speed Key Independent AES Based Authenticated Encryption Architecture using FPGAs "International Journal of Engineering and Technology(UAE), ISSN No: 2227-524X, Vol No: 7, Issue No: 1.5, Page No: 230-233, January 2018.

[19] G.S.Spandana, K Hari Kishore "A Contemporary Approach For Fault Diagnosis In Testable Reversible Circuits By Employing The CNT Gate Library" International Journal of Pure and Applied Mathematics, ISSN No: 1314-3395, Vol No: 115, Issue No: 7, Page No: 537-542, September 2017.

[20] K Hari Kishore, CVRN Aswin Kumar, T Vijay Srinivas, GV Govardhan, Ch Naga Pavan Kumar, R Venkatesh "Design and Analysis of High Efficient UART on Spartran-6 and Virtex-7 Devices", International Journal of Applied Engineering Research,
ISSN 0973-4562, Volume 10, Number 09, pp. 23043-23052, June 2015

[21] K Bindu Bhargavi, K Hari Kishore "Low Power BIST on Memory Interface Logic", International Journal of Applied Engineering Research, ISSN 0973-4562, Volume 10, Number 08 , pp. 21079 21090, May 2015.

[22] Korraprolu Brahma Reddy, K Hari Kishore, “A Mixed Approach for Power Dissipation Reduction in Nanometer CMOS VLSI circuits", International Journal of Applied Engineering Research, ISSN 0973-4562 Volume 9, Number 18 , pp. 5141-5148, July 2014.

[23] Nidamanuri Sai Charan, Kakarla Hari Kishore "Reorganization of Delay Faults in Cluster Based FPGA Using BIST" Indian Journal of Science and Technology, ISSN No: 0974-6846, Vol No.9, Issue No.28, page: 1-7, July 2016.

[24] Sravya Kante, Hari Kishore Kakarla, Avinash Yadlapati,"Design and Verification of AMBA AHB-Lite protocol using Verilog HDL" International Journal of Engineering and Technology, EISSN No: 0975-4024, Vol No.8, Issue No.2, Page:734-741, AprilMay 2016.

[25] Bandlamoodi Sravani, K Hari Kishore, "An FPGA Implementation of Phase Locked Loop (PLL)", International Journal of Applied Engineering Research, ISSN 0973-4562, Volume 10, Number 14, pp. 34137-34139, August 2015

[26] Avinash Yadlapati, Kakarla Hari Kishore,"Constrained Level Validation of Serial Peripheral Interface Protocol", Proceedings of the First International Conference on SCI 2016, Volume 1, Smart Computing and Informatics, Smart Innovation, Systems and Technologies 77, ISSN No: 2190-3018, ISBN: 978-981-10-55447, Chapter No: 77, pp. 743-753, 25 ${ }^{\text {th }}$ December 2017.

[27] P Kiran Kumar, P Prasad Rao, Kakarla Hari Kishore, “Optimal Design of Reversible Parity Preserving New Full Adder / Full Subtractor", IEEE SPONSORED 3rd INTERNATIONAL CONFERENCE ON ELECTRONICS AND COMMUNICATION SYSTEMS (ICECS 2016), pp. 3465-3470, $25^{\text {th }}$ and $26^{\text {th }}$ February 2016.

[28] Y Avinash, K Hari Kishore 'Designing Asynchronous FIFO for Low Power DFT Implementation'’ International Journal of Pure and Applied Mathematics, ISSN No: 1314-3395, Vol No: 115, Issue No: 8, Page No: 561-566, September 2017

[29] Mahesh Mudavath and K Hari Kishore "Design of RF Front End CMOS Cascade CS Low Noise Amplifier on 65nm Technology Process" International Journal of Pure and Applied Mathematics, ISSN No: 1314-3395, Vol No: 115, Issue No: 7, Page No: $417-$ 422, September 2017.

[30] P. Sahithi K Hari Kishore, E Raghuveera, P. Gopi Krishna "DESIGN OF VOLTAGE LEVEL SHIFTER FOR POWEREFFICIENT APPLICATIONS USING 45nm TECHNOLOGY" International Journal of Engineering and Technology(UAE), ISSN No: 2227-524X, Vol No: 7, Issue No: 2.8, Page No: 103-108, March 2018.

[31] N Bala Dastagiri K Hari Kishore "A 14-bit 10kS/s Power Efficient $65 \mathrm{~nm}$ SAR ADC for Cardiac Implantable Medical Devices" International Journal of Engineering and Technology(UAE), ISSN No: 2227-524X, Vol No: 7, Issue No: 2.8, Page No: 34-39, March 2018.

[32] Dr. Seetaiah Kilaru, Hari Kishore K, Sravani T, Anvesh Chowdary L, Balaji T "Review and Analysis of Promising Technologies with Respect to fifth Generation Networks", 2014 First International Conference on Networks \& Soft Computing, ISSN:978-1-4799-3486-7/14,pp.270-273,August2014.

[33] Meka Bharadwaj, Hari Kishore "Enhanced Launch-Off-Capture Testing Using BIST Designs" Journal of Engineering and Applied Sciences, ISSN No: 1816-949X, Vol No.12, Issue No.3, page: 636-643, April 2017.

[34] P Bala Gopal, K Hari Kishore, R.R Kalyan Venkatesh, P Harinath Mandalapu "An FPGA Implementation of On Chip UART Testing with BIST Techniques", International Journal of Applied Engineering Research, ISSN 0973-4562, Volume 10, Number 14 , pp. 34047-34051, August 2015

[35] A Murali, K Hari Kishore, D Venkat Reddy "Integrating FPGAs with Trigger Circuitry Core System Insertions for Observability in Debugging Process" Journal of Engineering and Applied Sciences, ISSN No: 1816-949X, Vol No.11, Issue No.12, page: 2643-2650, December 2016.

[36] Mahesh Mudavath, K Hari Kishore, D Venkat Reddy "Design of CMOS RF Front-End of Low Noise Amplifier for LTE System Applications Integrating FPGAs" Asian Journal of Information Technology, ISSN No: 1682-3915, Vol No.15, Issue No.20, page: 4040-4047, December 2016. 
[37] N Bala Dastagiri, Kakarla Hari Kishore "Reduction of Kickback Noise in Latched Comparators for Cardiac IMDs" Indian Journal of Science and Technology, ISSN No: 0974-6846, Vol No.9, Issue No.43, Page: 1-6, November 2016.

[38] S Nazeer Hussain, K Hari Kishore "Computational Optimization of Placement and Routing using Genetic Algorithm" Indian Journal of Science and Technology, ISSN No: 0974-6846, Vol No.9, Issue No.47, page: 1-4, December 2016.

[39] N Bala Dastagiri, K Hari Kishore "Analysis of Low Power Low Kickback Noise in Dynamic Comparators in Pacemakers" Indian Journal of Science and Technology, ISSN No: 0974-6846, Vol No.9, Issue No.44, page: 1-4, November 2016.

[40] Shaik Razia, P.Swathi Pryathyusha, N.Vamsi Krishna "A Comparative study of machine learning algorithms on thyroid disease prediction" International Journal of Engineering and Technology(UAE), ISSN No: 2227-524X, Vol No: 7, Issue No: 2.8, Page No: 315-319, March 2018

[41] S RAZIA, A REVIEW ON DISEASE DIAGNOSIS USING MACHINE LEARNING TECHNIQUES, International Journal of Pure and Applied Mathematics, ISSN No: 1314-3395, Vol No: 117, Issue No: 16, Page No: 79-85, 2017

[42] S Razia, MR Narasingarao, GR Sridhar, "A decision support system for prediction of thyroid disease-a comparison of multilayer perception neural network and radial basis function neural network", Journal of Theoretical and Applied Information Technology, ISSN 1992-8645, Volume 80, No. 3 , pp. 544, 2015

[43] SHAIK RAZIA, M.R.Narasingarao, "Development and Analysis of Support Vector Machine Techniques for Early Prediction of Breast Cancer and Thyroid" Journal of Advanced Research in Dynamical and Control Systems, ISSN: 1943-023X, Vol.9.Sp.Issue:6, page no: 869-878, 2017.

[44] S.V.Manikanthan and T.Padmapriya "Recent Trends In M2m Communications In 4g Networks And Evolution Towards 5g", International Journal of Pure and Applied Mathematics, ISSN NO: 1314-3395, Vol-115, Issue -8, Sep 2017.

[45] S.V. Manikanthan, T. Padmapriya "An enhanced distributed evolved node-b architecture in 5G tele-communications network" International Journal of Engineering \& Technology (UAE), Vol 7 Issues No (2.8) (2018) 248-254.March2018.

[46] S.V. Manikanthan, T. Padmapriya, Relay Based Architecture For Energy Perceptive For Mobile Adhoc Networks, Advances and Applications in Mathematical Sciences, Volume 17, Issue 1, November 2017, Pages 165-179 